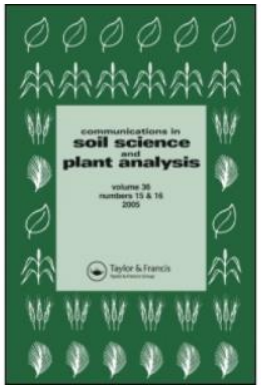

\title{
Analysis of Oil Content in Jatropha by Nuclear Magnetic Resonance Spectrometry
}

\author{
Kanwar L. Sahrawat ${ }^{*}$, P. V. Rao ${ }^{\text {a }}$, K. Srinivasu \& S. P. Wani ${ }^{\text {a }}$
}

${ }^{a}$ International Crops Research Institute for the Semi-Arid Tropics (ICRISAT), Patancheru 502 324, Andhra Pradesh, India

\author{
Published online: 14 Apr 2014
}

Communications in Soil Science and Plant Analysis

DOI: http://dx.doi.org/10.1080/00103624.2013.875201

This is author version post print archived in the official Institutional Repository of ICRISAT wWw.icrisat.org

Analysis of Oil Content in Jatropha by Nuclear Magnetic Resonance Spectrometry KANWAR L. SAHRAWAT, P. V. RAO, K. SRINIVASU AND S. P. WANI

International Crops Research Institute for the Semi-Arid Tropics (ICRISAT), Patancheru 502 324, Andhra

Pradesh, India

Thirty two diverse Jatropha curcas L. cultivars were analyzed for their oil content by the standard Soxhlet extraction method using hexane as solvent. The results were then compared with those obtained by nuclear magnetic resonance (NMR) spectrometer. The cultivars had a wide range in oil content, which ranged from 4.8 to $38.8 \%$ by the Soxhlet method; and from 6.0 to $38.9 \%$ by the NMR method. The values 
of oil content determined by the NMR method were highly significantly correlated $\left(R^{2}=0.9929\right.$, $p<0.0001, n=32$ ) with those obtained using the Soxhlet method. The NMR method is simple, nondestructive, rapid and accurate for the routine analysis of oil content in Jatropha.

Keywords Routine nondestructive method, Jatropha curcas, NMR spectrometer, oil content

Address correspondence to K. L. Sahrawat, international crops Research Institute for the Semi-Arid Tropics (ICRISAT), Patancheru 502 324, Andhra Pradesh, India. Email: k.sahrawat@cgiar.org 


\section{Introduction}

Nuclear Magnetic Resonance (NMR) Spectrometry has been used for determining oil content in seeds of various oil seed crops. The technique has been calibrated for several oil seed crops including groundnut, soybean and canola; and moreover, the technique can be calibrated for other species as needed (Madsen 1976; Jambunathan et al. 1985; Rubel 1994; Kaushik et al. 2007).

The use of the pulsed NMR technique has also been standardized to simultaneously determine oil and moisture content in small- as well large-seeded crops such as rape seed, soybean, maize or groundnut (Gambhir and Agarwala 1985; Jambunathan et al. 1985; Rubel 1994). In brief, NMR spectrometry provides a rapid, accurate and non-destructive estimation of oil content in whole intact seeds of a range of crops; and the technique is most suited for large volume routine analysis for oil content in crops as needed in conventional and molecular breeding research.

The aim of this communication is to describe the results of a study conducted for the comparative evaluation of the NMR spectrometry and the Soxhlet extraction methods for determining oil content in Jatropha curcas L. seeds. Jatropha is emerging as a potential crop in meeting the challenge of shortage of non-edible oil for biodiesel (Achten et al. 2010; Behera et al. 2010; Brittaine 2008; Koh and Ghazi 2011). The research on Jatropha has also shown that there is a large variability in different accessions of Jatropha from diverse agroclimatic regions (Kaushik et al. 2007; Divakara et al. 2010).

Moreover, recent research at the ICRISAT (International Crops Research Institute for the SemiArid Tropics) showed that Jatropha has the potential to grow on relatively degraded, low fertility lands; and has the capacity to rehabilitate the degraded lands by adding large amounts of carbon through litter and leaf fall, and pruned biomass (Wani et al. 2012). 


\section{Materials and Methods}

Jatropha seeds were received in our laboratory from plant breeders involved in research on Jatropha research at the International Crops Research Institute for the Semi-Arid Tropics (ICRISAT), Patancheru, India, for determining oil content. This provided us the opportunity to calibrate the NMR method for determining oil contents in Jatropha cultivars/accessions using Soxhlet extraction as the standard method. The results obtained by the NMR method were evaluated by comparing them with those obtained by the Soxhlet extraction method using hexane as the solvent.

While intact seeds of Jatropha cultivars were used for the analysis of their oil contents by the NMR method; the Jatropha seeds were ground in a Krups, KM 75 (Robert Krups, 5650 Solingen, Germany) blender; and the Jatropha meal was extracted with hexane for $18 \mathrm{~h}$ in a Soxhlet apparatus. Oil content was adjusted to 5\% moisture content. For the NMR method, Bench top NMR (MQA-6005, Oxford Instruments, UK) spectrometer was used. Detailed description of the NMR and Soxhlet methods used for determining oil content in Jatropha cultivars are described in Jambunathan et al. (1985).

The oil content by the NMR and Soxhlet methods was determined using two replications (two independent analyses) and the values reported are the means of two replications. The values of oil content reported are adjusted to $5 \%$ moisture content.

Simple correlation between the values of oil content determined by the NMR and Soxhlet methods was obtained by regression analysis.

\section{Results and Discussion}


The oil content in 32 Jatropha cultivars analyzed using the Soxhlet and NMR methods are given in Table 1. The results showed that the Jatropha cultivars used in the study captured a wide diversity in oil contents. For example, the oil content analyzed using the Soxhlet extraction method varied from 4.8 to $38.8 \%$ with a mean value of $22.23 \%$. The oil content in the Jatropha cultivars analyzed by the NMR method ranged from 6.0 to $38.9 \%$ with a mean value of $22.99 \%$.

The results on the precision in determining oil content by the Soxhlet and NMR methods as judged by the range, mean and standard deviation (SD) and standard error (SE) showed that the two methods had acceptable precision in the analysis of oil content in Jatropha cultivars (Table 2). However, the precision by the NMR method seemed better with relatively lower values of SD and SE in the determination of oil content.

Regression analysis of the results on oil content of 32 Jatropha cultivars showed that the values obtained by the NMR method were highly significantly correlated with those obtained by the Soxhlet extraction method. The regression equation showing the relationships between the two methods is represented by the following equation:

Oil by Soxhlet method $=1.0659$ (Oil by NMR method) $-2.0786, R^{2}=0.9929(P<0.0001, n=32)$

As mentioned in the Introduction, the NMR method is a very versatile method and can be adopted for the analysis of oil and moisture contents in a range of crops with a wide range in oil contents. Our results on the analysis of oil contents in diverse Jatropha cultivars indeed establish that the NMR is a convenient, rapid and accurate and non-destructive method for routine analysis of oil content in non-edible seed crop like Jatropha. This should aid breeders in the selection and breeding of Jatropha for enhanced oil content (Kaushik et al. 2007; Divakara et al. 2010).

\section{References}

Achten, W. M. J., J. Almeida, V. Fobelets, E. Bolle, E. Mathijs, V. P. Singh, D. N. Tewari, L. V. Verchot, 
and B. Muys. 2010. Life cycle assessment of Jatropha biodiesel as transportation fuel in rural India. Applied Energy 87:3652-3660.

Behera, S. K., P. Srivastava, R. Tripathi, J. P. Singh, and N. Singh. 2010. Evaluation of plant performance of Jatropha curcas L. under different agro-practices for optimizing biomass - a case study. Biomass Bioenergy 34:30-41.

Brittaine, R. 2008. Looking at new biofuel crops for small farmers in developing countries. Agricultural Development 2:13-17.

Divakara, B. N., H. D. Upadhyaya, S. P. Wani, and C. L. L. Gowda. 2010. Biology and genetic improvement of Jatropha curcas L., a review. Applied Energy 87:732-742.

Gambhir, P. N., and A. K. Agarwala. 1985. Simultaneous determination of moisture and oil content in oilseeds by pulsed nuclear magnetic resonance. Journal of the American Oil Chemists' Society 62:103-108.

Jambunathan, R., S. M. Raju, and S. P. Barde. 1985. Analysis of oil content of groundnuts by nuclear magnetic resonance spectrometry. Journal of the Science of Food and Agriculture 36:162-166.

Kaushik, N., K. Kumar, S. Kumar, N. Kaushik, and S. Roy. 2007. Genetic variability and divergence studies In seed traits and oil content of Jatropha (Jatropha curcas L.) accessions. Biomass Bioenergy 31: 497-502. 
Koh, M. Y. and T. I. D. Ghazi. 2011. Review of biodiesel production from Jatropha curcas L. oil.

Renewable Sustainable Energy Review 15:2240-2251.

Madsen, E. 1976. Nuclear magnetic resonance spectrometer as a quick method of determination of oil content in rape seed. Journal of the American Oil Chemists' Society 53:467-469.

Rubel, G. J. 1994. Simultaneous determination of oil and water contents in different oilseeds by pulsed nuclear magnetic resonance. Journal of the American Oil Chemists' Society 71:1057-1062.

Wani, S. P., G. Chander, K. L. Sahrawat, Ch. Srinivasa Rao, G. Raghvendra, P. Susanna, and M. Pavani. 2012. Carbon sequestration and land rehabilitation through Jatropha curcas (L.) plantation in degraded lands. Agriculture, Ecosystems and Environment 161:112-120. 
Table 1. The oil content in 32 Jatropha cultivars/accessions determined by the Soxhlet extraction and NMR methods

\begin{tabular}{|c|c|c|}
\hline \multirow[t]{2}{*}{ Sample No. } & \multicolumn{2}{|c|}{ Oil content (\%) } \\
\hline & Soxhlet method & NMR method \\
\hline 1 & 23.5 & 25.5 \\
\hline 2 & 16.7 & 18.0 \\
\hline 3 & 15.1 & 16.8 \\
\hline 4 & 15.5 & 16.0 \\
\hline 5 & 11.2 & 12.9 \\
\hline 6 & 36.8 & 36.1 \\
\hline 7 & 13.8 & 15.5 \\
\hline 8 & 13.6 & 15.8 \\
\hline 9 & 37.0 & 36.2 \\
\hline 10 & 30.3 & 30.9 \\
\hline 11 & 32.3 & 33.7 \\
\hline 12 & 38.8 & 37.0 \\
\hline 13 & 15.5 & 16.9 \\
\hline 14 & 11.9 & 13.6 \\
\hline 15 & 9.1 & 10.7 \\
\hline 16 & 35.2 & 36.2 \\
\hline 17 & 14.7 & 13.6 \\
\hline 18 & 35.9 & 36.6 \\
\hline 19 & 11.4 & 13.0 \\
\hline 20 & 19.3 & 20.6 \\
\hline 21 & 14.9 & 16.2 \\
\hline 22 & 18.2 & 18.9 \\
\hline 23 & 36.9 & 36.3 \\
\hline 24 & 37.2 & 38.9 \\
\hline 25 & 13.2 & 14.4 \\
\hline 26 & 10.1 & 11.4 \\
\hline 27 & 30.0 & 31.2 \\
\hline 28 & 13.8 & 14.5 \\
\hline 29 & 19.4 & 20.1 \\
\hline 30 & 4.8 & 6.0 \\
\hline 31 & 36.7 & 35.3 \\
\hline 32 & 38.4 & 37.0 \\
\hline
\end{tabular}


Table 2. Precision in the analysis of soil content in Jatropha seeds by Soxhlet and NMR methods

\begin{tabular}{|c|c|c|}
\hline \multirow{2}{*}{} & \multicolumn{2}{|c|}{ Oil content (\%) } \\
\cline { 2 - 3 } & Soxhlet method & NMR method \\
\hline Range & $4.8-38.8$ & $6.0-38.9$ \\
\hline Mean & 22.23 & 22.99 \\
\hline SD & 11.04 & 10.42 \\
\hline SE & 1.952 & 1.841 \\
\hline
\end{tabular}

